\title{
Prevalence and Predictors of PTSD during the Containment Stage of COVID-19 Epidemic among College Female Students in China
}

\section{Mingyu Si}

Chinese Academy of Medical Sciences and Peking Union Medical College https://orcid.org/0000-00028372-9301

Xiaoyou Su ( $\square$ suxiaoyou@hotmail.com )

https://orcid.org/0000-0002-4216-2142

\section{Yu Jiang}

CAMS PUMC: Chinese Academy of Medical Sciences and Peking Union Medical College

\section{Wenjun Wang}

Jining Medical University

Xiaofen Gu

Xinjiang Medical University Affiliated Tumor Hospital

\section{Li Ma}

Dalian Medical University

Jing Li

Sichuan University West China School of Public Health

\section{Shaokai Zhang}

Henan Provincial Tumor Hospital: Henan Cancer Hospital

\section{Zefang Ren}

Sun Yat-Sen University School of Public Health

\section{Yuanli Liu}

CAMS PUMC: Chinese Academy of Medical Sciences and Peking Union Medical College

\section{Youlin Qiao}

CAMS PUMC: Chinese Academy of Medical Sciences and Peking Union Medical College

\section{Research article}

Keywords: COVID-19, College female students, China, Post-traumatic stress disorder, PTSD

Posted Date: April 1st, 2021

DOI: https://doi.org/10.21203/rs.3.rs-368796/v1 
License: (c) (i) This work is licensed under a Creative Commons Attribution 4.0 International License. Read Full License 


\section{Abstract}

Background College students are a uniquely vulnerable group and may experience high stress levels due to COVID-19, especially for girls. This study aims to identify the post-traumatic stress disorder (PTSD) symptoms and related factors among the target population during the initial phases of the COVID-19 pandemic.

Methods A cross-sectional online survey was conducted during the initial phases of the COVID-19 pandemic in China. A total of 2205 college female students from six provinces enrolled in this study and completed the questions about cognitive status of COVID-19, the Impact of Event Scale-6 (IES-6), the Multidimensional Perceived Social Support Scale (MPSSS) and a self-developed 10-item Perceived threat scale. Univariate and multivariate logistic regression were performed by SPSS software to explore the determinants of PTSD symptoms.

Results PTSD symptoms were prevalent in this sample of college female students, and $34.20 \%$ met the cut-off for PTSD. Self-reported fair or poor health (AOR=1.78, 95\%Cl: 1.22-2.59), high concern about COVID-19 (AOR=1.66, 95\%Cl: 1.35-2.03), beliefs that 'COVID-19 can cause a global outbreak' (AOR=1.26, $95 \% \mathrm{Cl}$ : 1.02-1.56), the perception of 'risk of infection' (AOR=2.46,95\%Cl: 2.16-2.81), beliefs that 'closed management' and 'COVID-19 as a public health emergency of international concern' would have an impact, and the fear of 'impact on life planning' were all positively associated with PTSD (AOR=1.37, 1.22 and 1.29, respectively), whereas perceived social support from family ( $A O R=0.81,95 \% \mathrm{Cl}$ : $0.70-0.93$ ) was negatively associated with PTSD. Among the significant variables at the bivariate level, multivariate logistic regression revealed that the greatest protector for PTSD was the high knowledge score $(A O R=0.73,95 \% \mathrm{Cl}: 0.60-0.90)$, while had confirmed cases among relatives and friends $(\mathrm{AOR}=7.70,95 \% \mathrm{Cl}$ : 1.28-46.25) was the strongest predictor of PTSD.

Conclusions In summary, PTSD symptoms were prevalent among college female students in China during the COVID-19 epidemic. Targeting vulnerable populations to improve their knowledge of COVID-19 and create an atmosphere of social support would be beneficial to improve the mental health of the female students during the COVID-19 epidemic.

\section{Background}

An outbreak of the Coronavirus Disease 19 (COVID-19) infection began in December 2019 and as of November 15, 2020 has resulted in 53,766,728 cases and 1,308,975 deaths worldwide [1]. In China alone, there were 92,452 reported cases and 4,749 people have died due to COVID-19 [2]. Given the serious situation with COVID-19, the World Health Organization (WHO) declared it a Public Health Emergency of International Concern (PHEIC) on January 30, 2020 and due to unprecedented spread of the virus it was redefined as a global pandemic on March 11, 2020 [3]. Since the beginning of the outbreak many countries have adopted strict measures to control the outbreak, including nationwide lockdown, home isolation, quarantine, and social distancing. 
The COVID-19 pandemic has caused enormous psychological impact worldwide [4-6]. Globally, relatively high rates of symptoms of post-traumatic stress disorder (PTSD) (7-53.8\%) were reported in the general population during the COVID-19 pandemic, especially in college students [6-10]. Exposure to such stressful events can lead to the development of acute stress disorder and finally PTSD, if symptoms persist. At the end of February, college students in China were notified that the start of school would be postponed. They could not resume school at the normally scheduled time, their regular routines of study were disrupted, and at the same time they were youths who were still developing self-discipline and emotional control [11]. In a study among college students in mainland China during the beginning of COVID-19 outbreak, $30.8 \%$ ( $95 \% \mathrm{Cl}$ : 28.8 to $32.8 \%$ ) of the participants completing the survey presented clinically relevant PTSD symptoms [9].

Females are usually more likely to have mental health problems than males when they are facing stressful events. Due to sex hormones such as oestradiol and progesterone and the life trajectory they experience, they always worry about interpersonal stressors, gender-based violence, lack of gender equality and discrimination compare to the similar-age male $[12,13]$. Studies showed that the home isolation due to COVID-19 was associated with a worse psychological status with a stronger association in women in comparison to men [14]. PTSD was especially one of the most prevalent long-term psychiatric disorders for females when they were facing traumatic events [15-17]. Previous studies indicated that acute psychological disorders and PTSD symptoms were more prevalent in females than males after traumatic events [18-20]. A study conducted in South Lebanon revealed that females were twice in the prevalence of PTSD as likely as males after experienced the 2006 war (24.3 vs. 10.4\%) [19]. Similarly, among Indian females and males affected by flash floods in $2010,22.3 \%$ and $18.1 \%$ met the diagnostic criteria for PTSD, respectively [20].

Given the dispositional traits of female and situational influences of COVI-19 to the university students, this study aims to focus on female college students and identify the PTSD symptoms and related factors of this vulnerable group during the initial phases of the COVID-19 pandemic through a multi-center survey. The results of this study may assist government and healthcare agencies in developing interventions by better understanding the causes of adverse psychological outcomes to alleviate stress in college students, especially for female students in the event of future outbreaks of infectious diseases.

\section{Methods}

\subsection{Settings and participants}

We conducted a cross-sectional survey from February 23 to March 5, 2020, when the COVID-19 outbreak showed a downward trend of new cases in China and an upward trend overseas. Due to the isolation and social distancing measures recommended by the Chinese government, the questionnaire survey and corresponding data were collected electronically via the internet. In mainland China, potential participants from six universities (University of Jinan, Sichuan University, Sun Yat-sen University, Shanxi University of 
Chinese Medicine, Henan University of Engineering and Dalian University of Technology) located in different geographical territories were electronically invited by partner teachers in each university.

The study was approved by the Ethics Committee of Jining Medical University of Shandong Province on February 12,2020 . To ensure the authenticity and representativeness of the survey, our research was based on voluntary participation without any compensation measures, and potential participants provided electronic informed consent if they were willing to participate in the questionnaire survey voluntarily. The participants have to meet the following criteria: (1) college female students; (2) aged $\geq 18$ years; and (3) proficiency in Chinese. After passing the qualification review and answering yes to the participation question, they were directed to complete the self-reported questionnaire.

\subsection{Measurements}

The structured questionnaire was designed to encompass the following areas: (1) demographic characteristics such as age, major and health status,etc. (2) variables related to COVID-19 (e.g. awareness of COVID-19, levels of concern to the outbreak), (3) daily perceived social support, (4) perceived threat associated with COVID-19, (5) PTSD. PTSD, perceived threat, and perceived social support were measured as outlined in the following.

\subsubsection{Impact of Event Scale-6}

The Impact of Event Scale-6 (IES-6) is an abbreviated 6-item version of The Impact of Event Scale-revised, which has been widely accepted as a core outcome measure for PTSD in critical illness survivorship research $[21,22]$. Respondents are asked to report the psychological impact after exposure to a crisis situation within 7 days of exposure using a 5 -point Likert scale $(0=$ not at all; $4=$ extremely), and PTSD is measured when the score of IES- 6 is greater than or equal to 10 [21]. In the present study, the Cronbach's a was 0.84 .

\subsubsection{The Perceived threat scale}

To measure the extent of threat to which participants perceived from COVID-19 pandemic, the 10-Item perceived threat scale was developed. The items were based on earlier studies [23-25], each item can be rated on a scale from 1 (Strongly disagree) to 5 (Strongly agree). Exploratory factor analysis on the 10 items of perceived threat yielded three dimensions: Risk of infection, Impact on life planning, and Impact of PHEIC. The three dimensions of the perceived threat scale were proved to have satisfied content and concurrent validity. Sample items includes: 'I feel anxious and scared when thinking of COVID-19'. In the present study, the Cronbach's a for the three dimensions were $0.83,0.84$ and 0.88 , respectively (See Appendix 1 and 2).

\subsubsection{The Multidimensional Scale of Perceived Social Support (MSPSS)}


The 12-item perceived social support scale (MSPSS) assesses a respondent's perceived support on a 7point Likert scale ( 1 = strongly disagree; 7 = strongly agree) [26]. Total possible scores range from 12 to 84, with higher scores indicating higher levels of perceived support obtained from family, friends and significant others. The Chinese version of the MSPSS has adequate internal consistency in eariler study and in present study (Cronbach's a 0.89 and 0.94, respectively) [27]. The Cronbach's a for family, friends and significant others were $0.88,0.92$ and 0.87 , respectively.

\subsection{Statistical Analysis}

The data were analyzed using SPSS 23.0. A descriptive analysis of the demographic data was conducted to describe the sample characteristics. Categorical variables were expressed as frequencies and percent distributions, while continuous variables were presented as means \pm standard deviations (SD). The prevalence of PTSD was derived according to the cut-off values routinely used in previous studies. Bivariate generalized linear modeling with a binary logistic distribution was conducted to examine background and other variables related to PTSD. Variables that were significant at the bivariate level $(\mathrm{P}<$ 0.1 ) were adjusted in further multivariate analysis for factors related to PTSD. A value of $P<0.05$ was considered statistically significant in multivariate analysis. The results were reported as odds ratios (ORs) and adjusted odds ratios (AORs).

\section{Results}

\subsection{Background characteristics}

A total of 2205 individuals participated in the questionnaire survey with a mean age of 20.85 years (SD, 1.50 years; range, $18-26$ years). Among participants, $96.78 \%$ were Han Chinese, $60.09 \%$ were rural residents, $45.90 \%$ were majored in medicine, $1.86 \%$ ever had at least one of the chronic diseases (e.g. diabetes, cardiovascular diseases) and $93.15 \%$ reported they have good health status. The mean score of perceived support from family, friends and significant others was $5.65,5.60$, and 5.49 , respectively.

Among the participants, $41.54 \%$ had been quarantined or isolated due to the COVID-19 pandemic, 3.76\% had close relatives and friends in key epidemic areas. $85.62 \%$ reported there were confirmed cases in their current living city, $3.81 \%$ in their current community or village, and $0.41 \%$ among their relatives and friends (Table 1). 
Table 1

Background characteristics of college female students $(n=2205)$

\begin{tabular}{|c|c|c|}
\hline Variables & $\mathbf{n}$ & $\%$ \\
\hline \multicolumn{3}{|c|}{ Socio-demographics } \\
\hline Age (Years) & \multicolumn{2}{|c|}{$20.85 \pm 1.50$} \\
\hline $18-20$ & 1030 & 46.71 \\
\hline $21+$ & 1175 & 53.29 \\
\hline \multicolumn{3}{|l|}{ Ethnicity } \\
\hline Han & 2134 & 96.78 \\
\hline Other & 71 & 3.22 \\
\hline \multicolumn{3}{|l|}{ Residence place } \\
\hline Urban & 880 & 39.91 \\
\hline Rural & 1325 & 60.09 \\
\hline \multicolumn{3}{|l|}{ Major } \\
\hline Medical & 1012 & 45.90 \\
\hline Non-medical & 1193 & 54.10 \\
\hline \multicolumn{3}{|c|}{ Ever had chronic disease(s) } \\
\hline No & 2164 & 98.14 \\
\hline Yes & 41 & 1.86 \\
\hline \multicolumn{3}{|l|}{ Health condition } \\
\hline Good health & 2054 & 93.15 \\
\hline Fair or poor health & 151 & 6.85 \\
\hline \multicolumn{3}{|c|}{ Perceived social support (Mean \pm SD) } \\
\hline Family & \multicolumn{2}{|c|}{$5.65 \pm 1.03$} \\
\hline Friends & \multicolumn{2}{|c|}{$5.60 \pm 0.96$} \\
\hline Significant other & \multicolumn{2}{|c|}{$5.49 \pm 0.98$} \\
\hline \multicolumn{3}{|c|}{ Isolating status and confirmed cases around } \\
\hline Ever been quarant & & \\
\hline
\end{tabular}




\begin{tabular}{|lll|}
\hline Variables & $\mathbf{n}$ & $\%$ \\
\hline No & 1289 & 58.46 \\
\hline Yes & 916 & 41.54 \\
\hline Have close relatives and friends in key epidemic areas & & \\
\hline No & 2122 & 96.24 \\
\hline Yes & 83 & 3.76 \\
\hline Confirmed cases in my current city & & \\
\hline No or not sure & 317 & 14.38 \\
\hline Yes & 1888 & 85.62 \\
\hline Confirmed cases in my current community or village & & \\
\hline No or not sure & 2121 & 96.19 \\
\hline Yes & 84 & 3.81 \\
\hline Confirmed cases among relatives and friends & & \\
\hline No & 2196 & 99.59 \\
\hline Yes & 9 & 0.41 \\
\hline
\end{tabular}

\subsection{Knowledge, awareness and perceived threat of COVID-19 pandemic}

Table 2 shows the fourteen questions about COVID-19 knowledge and the correct rate of the participants, with a mean score of 10.58 (SD, 1.30; range, 4-14; median, 11). Nearly all respondents knew that the first case of COVID-19 was diagnosed in Wuhan, China (98.96\%). 95.01\% could identify that the novel coronavirus 2019 (2019-nCoV) is not an influenza virus. 95.19\% understood the difference between SARS and COVID-19, and $94.01 \%$ agreed that the influenza vaccine cannot prevent COVID-19. The majority of the participants knew the suspected source of 2019-nCoV (99.41\%), the incubation period of the virus infection (90.61\%), and its infectiousness during the incubation period $(99.09 \%)$. In contrast, only $11.07 \%$ knew that COVID-19 is mainly transmitted by droplets and contact and $11.88 \%$ knew that fever, fatigue and dry coughing are considered the main clinical manifestations of COVID-19 infection. About half of the participants clearly knew the official management regulation of Covid-19 as infectious disease (51.97\%) and susceptible population (46.67\%) of COVID-19 in China. As for prevention and treatment knowledge, $85.90 \%$ were aware that there is no special treatment for COVID-19, $80.36 \%$ recognized the efficacy of preventive masks, and $87.26 \%$ mastered the correct way to wear preventive masks during the current epidemic. 
Page 9/27 
Table 2

Knowledge about COVID-19 and the correct rate of participants $(\mathrm{N}=2205)$

\section{Questions(correct rate, \% of the total Options sample)}

1. Where was the first case of the COVID-19 outbreak? (98.96\%)

2. Do you agree: the new coronavirus is the influenza virus. (95.01\%)

3. Do you agree: COVID-19 is SARS. $(95.19 \%)$

4. Do you agree: influenza or pneumonia vaccine can prevent COVID-19. (94.01\%)

5. What category is COVID-19 in legal management of infectious diseases in China? (51.97\%)

6. What is the possible source of the new coronavirus? (99.41\%)

7. How is the new coronavirus spread? (11.07\% and $22.31 \%)$

8. What is the susceptible population of COVID-19? (46.67\%)

9. What is the incubation period of new coronavirus infection? (90.61\%)

10. Is there infectiousness during the incubation period of new coronavirus infection? (99.09\%)

11. Typical symptoms of new coronavirus infection? (11.88\% and $12.38 \%)$

12. Is there any specific treatment for COVID-19? (85.90\%)

13. Which types of masks can prevent COVID-19? (80.36\% and $89.16 \%)$

14. What is the correct way to wear the mask during the current epidemic? (87.26\%)
Beijing; Wuhan; Guangzhou; Hongkong

Agree; Disagree

Agree; Disagree

Agree; Disagree

Category $A$; Category $B$, but managed according to category $A_{i}$ Category C; I don't know

Wild animals, such as bats; Poultry, such as chickens; Livestock, such as pigs; I don't know

Fecal-oral transmission; Respiratory tract droplet transmission; Aerosol transmission; Indirect contact transmission; Mother-to-child transmission; I don't know

Middle-aged and elderly; The elderly and children; Generally susceptible; Young and middle-aged crowd

Within 24 hours; Within 2 days; $1-14$ days, mostly 3-7 days; Within 3 weeks

Yes; No

Fever; Fatigue; Dry coughing; Shortness of breath ; Dyspnea

Yes; No

Cotton mask; Sponge mask; Medical surgical mask; Activated carbon mask; N95, KN95, DS2, FFP2 masks

Wear masks whenever you go out; Wear masks only in populated areas (i.e. public transportation); Occasionally wear a mask; Never wear a mask

* Multiple choice questions with incomplete and complete correct rate; Mean knowledge score: 10.58 \pm 1.30 (range, 4-14; median, 11). 
Table 3 presents the knowledge score, awareness and perceived threat of COVID-19 among participants. $51.80 \%$ had a knowledge score $\geq 11$ (Mean score of participants). $85.80 \%$ of the respondents were aware of the news that the WHO defined COVID-19 as a PHEIC on January $30,42.31 \%$ were highly concerned about the epidemic, and $31.66 \%$ believed that COVID-19 would cause a global outbreak. In addition, $50.88 \%$ thought the closed-off management had impacted their daily lives. Regarding perceived threat of COVID-19, the mean score of risk of infection, impact on life planning and impact of PHEIC was 1.88, 3.10 , and 3.26 , respectively. 
Table 3

Knowledge, awareness and perceived threat of COVID-19 pandemic among college female students $(n=2205)$

\begin{tabular}{|c|c|c|}
\hline Variables & $\mathbf{n}$ & $\%$ \\
\hline \multicolumn{3}{|l|}{ Knowledge of COVID-19 } \\
\hline Score $<11$ & 1063 & 48.21 \\
\hline Score $\geq 11$ & 1142 & 51.79 \\
\hline \multicolumn{3}{|l|}{ Awarenessof COVID-19 } \\
\hline \multicolumn{3}{|c|}{ Knowing that the WHO declared COVID-19 as a PHEIC on January 30} \\
\hline No & 313 & 14.20 \\
\hline Yes & 1892 & 85.80 \\
\hline \multicolumn{3}{|l|}{ Levels of concern } \\
\hline Less concern & 1272 & 57.69 \\
\hline High concern & 933 & 42.31 \\
\hline \multicolumn{3}{|c|}{ COVID-19 is expected to cause a global outbreak } \\
\hline No & 1507 & 68.34 \\
\hline Yes & 698 & 31.66 \\
\hline \multicolumn{3}{|c|}{ Impact of closed management on life } \\
\hline No & 1083 & 49.12 \\
\hline Yes & 1122 & 50.88 \\
\hline \multicolumn{3}{|c|}{ Perceived threat of COVID-19 } \\
\hline Risk of infection & \multicolumn{2}{|c|}{$1.88 \pm 0.82$} \\
\hline Impact on life planning & \multicolumn{2}{|c|}{$3.10 \pm 0.97$} \\
\hline Impact of PHEIC & \multicolumn{2}{|c|}{$3.26 \pm 0.83$} \\
\hline
\end{tabular}

\subsection{Bivariate correlates of PTSD}

In the present study, the IES- 6 scale was used to measure the PTSD of COVID-19 outbreak, which revealed a sample mean score of $7.42(S D=4.87)$, and $732(34.20 \%)$ of participants were considered to have the PTSD symptom. 
Those who majored in non-medical $(\mathrm{OR}=1.23, \mathrm{P}=0.02)$ and self reported in fair or poor health $(\mathrm{OR}=2.10$, $\mathrm{P}=0.00$ ) were positively associated with PTSD, whereas perceived social support from family was negatively associated with PTSD $(O R=0.85, P=0.00)$. 'Ever been quarantined or isolated' was positively associated with PTSD $(O R=1.21, P=0.04)$. Having close relatives and friends in key epidemic areas $(\mathrm{OR}=1.49, \mathrm{P}=0.08)$ and having confirmed cases among relatives and friends $(\mathrm{OR}=7.10, \mathrm{P}=0.02)$ were positively associated PTSD, whereas having high knowledge of COVID-19 was negatively associated PTSD (OR=0.76, $P=0.00)$. High concern about the epidemic was positively correlated with PTSD $(O R=1.57, P=0.00)$, and those who believed COVID-19 would cause a global outbreak was significantly associated with PTSD (OR=1.79, $\mathrm{P}=0.00)$. In addition, beliefs that 'Impact of closed management on life' and perceived threat of COVID-19 in the three sub-dimensions were all positively associated with PTSD (Table 4). 
Table 4

Bivariate correlation of background, knowledge, awareness and perceived threat predicting PTSD ( $N=$ 2205)

\begin{tabular}{|c|c|c|c|c|c|}
\hline \multirow[t]{2}{*}{ Variables } & \multicolumn{5}{|l|}{ PTSD } \\
\hline & Yes[n(\%)] & No[n(\%)] & OR & $95 \% \mathrm{Cl}$ & $\mathbf{P}$ \\
\hline \multicolumn{6}{|l|}{ Socio-demographics } \\
\hline \multicolumn{6}{|l|}{ Age (Years) } \\
\hline $18-20$ & $337(32.72)$ & $693(67.28)$ & 1 & & \\
\hline $21+$ & 395(33.62) & $780(66.38)$ & 1.04 & $\begin{array}{l}0.87- \\
1.24\end{array}$ & 0.67 \\
\hline \multicolumn{6}{|l|}{ Ethnicity } \\
\hline Han & 710(33.27) & $1424(66.73)$ & 1 & & \\
\hline Other & 22(30.99) & $49(69.01)$ & 0.90 & $\begin{array}{l}0.54- \\
1.50\end{array}$ & 0.69 \\
\hline \multicolumn{6}{|l|}{ Residence place } \\
\hline Urban & 293(33.30) & $587(66.70)$ & 1 & & \\
\hline Rural & $439(33.13)$ & $886(66.87)$ & 0.99 & $\begin{array}{l}0.83- \\
1.19\end{array}$ & 0.94 \\
\hline \multicolumn{6}{|l|}{ Major } \\
\hline Medical & $311(30.73)$ & 701(69.27) & 1 & & \\
\hline Non-medical & $421(35.29)$ & 772(64.71) & 1.23 & $\begin{array}{l}1.03- \\
1.47\end{array}$ & $0.02^{\star *}$ \\
\hline \multicolumn{6}{|c|}{ Ever had chronic disease(s) } \\
\hline No & $17(41.46)$ & $24(58.54)$ & 1 & & \\
\hline Yes & 715(33.04) & 1449(67.96) & 0.70 & $\begin{array}{l}0.37- \\
1.31\end{array}$ & 0.26 \\
\hline \multicolumn{6}{|l|}{ Health condition } \\
\hline Good health & 657(31.99) & 1397(68.01) & 1 & & \\
\hline Fair or poor health & $75(49.67)$ & $76(50.33)$ & 2.10 & $\begin{array}{l}1.51- \\
2.93\end{array}$ & $0.00 * \star$ \\
\hline \multicolumn{6}{|c|}{ Perceived social support (Mean \pm SD) } \\
\hline Family & $5.65 \pm 1.03$ & & 0.85 & $\begin{array}{l}0.78- \\
0.92\end{array}$ & $0.00 * \star$ \\
\hline
\end{tabular}




\begin{tabular}{|c|c|c|c|c|c|}
\hline Variables & PTSD & & & & \\
\hline Friends & $5.60 \pm 0.96$ & & 0.96 & $\begin{array}{l}0.87- \\
1.05\end{array}$ & 0.34 \\
\hline Significant other & $5.49 \pm 0.98$ & & 0.93 & $\begin{array}{l}0.85- \\
1.12\end{array}$ & 0.10 \\
\hline $\begin{array}{l}\text { Isolating status a } \\
\text { around }\end{array}$ & & & & & \\
\hline Ever been quaran & & & & & \\
\hline No & $405(31.42)$ & $884(68.58)$ & 1 & & \\
\hline Yes & $327(35.70)$ & $589(64.30)$ & 1.21 & $\begin{array}{l}1.01- \\
1.45\end{array}$ & $0.04^{\star *}$ \\
\hline $\begin{array}{l}\text { Have close relativ } \\
\text { epidemic areas }\end{array}$ & & & & & \\
\hline No & 697(32.85) & $1425(67.15)$ & 1 & & \\
\hline Yes & $35(42.17)$ & $48(57.83)$ & 1.49 & $\begin{array}{l}0.96- \\
2.33\end{array}$ & $0.08 *$ \\
\hline There are confirm & & & & & \\
\hline No or not sure & $100(31.55)$ & $217(68.45)$ & 1 & & \\
\hline Yes & 632(33.47) & $1256(66.53)$ & 1.09 & $\begin{array}{l}0.85- \\
1.41\end{array}$ & 0.50 \\
\hline $\begin{array}{l}\text { There are confirm } \\
\text { community or vill }\end{array}$ & & & & & \\
\hline No or not sure & 702(33.10) & $1419(66.90)$ & 1 & & \\
\hline Yes & $30(35.71)$ & $54(64.29)$ & 0.89 & $\begin{array}{l}0.57- \\
1.40\end{array}$ & 0.62 \\
\hline $\begin{array}{l}\text { Confirmed cases } \\
\text { friends }\end{array}$ & & & & & \\
\hline No & 725(33.01) & 1471(66.99) & 1 & & \\
\hline Yes & $7(77.78)$ & $2(22.22)$ & 7.10 & $\begin{array}{l}1.47- \\
34.27\end{array}$ & $0.02^{\star *}$ \\
\hline Knowledge of $\mathrm{CO}$ & & & & & \\
\hline Score $<11$ & $386(36.31)$ & 677(63.69) & 1 & & \\
\hline Score $\geq 11$ & $346(30.30)$ & 796(69.70) & 0.76 & $\begin{array}{l}0.64- \\
0.91\end{array}$ & $0.00 \star *$ \\
\hline Awareness of $\mathrm{CO}$ & & & & & \\
\hline
\end{tabular}




\section{Variables}

PTSD

Knowing that the WHO declared COVID-19

as a PHEIC on January 30

No

Yes

Levels of concern

Less concern

High concern
102(32.59) 211(67.41) $\quad 1.00$

630(33.30) 1262(66.70) 0.97

$0.75-$

1.25

0.81

368(28.93) 904(71.07) 1

$364(39.01) \quad 569(60.00) \quad 1.57 \quad 1.31-\quad 0.00 * *$

COVID-19 is expected to cause a global

outbreak

$\begin{array}{lllllll}\text { No } & 437(29.00) & 1070(71.00) & 1 & & \\ \text { Yes } & 295(42.26) & 403(57.74) & 1.79 & \begin{array}{l}1.49- \\ \text { (2.16 }\end{array} & 0.00 * *\end{array}$

Impact of closed management on life

$\begin{array}{lllllll}\text { No } & 298(27.52) & 785(72.48) & 1 & & \\ \text { Yes } & 434(38.68) & 688(61.32) & 1.66 & 1.39- & 0.00 * * \\ & & & & 1.99 & \end{array}$

\section{Perceived threat of COVID-19}

\begin{tabular}{lcccc} 
Risk of infection & $1.88 \pm 0.81$ & 2.71 & $2.39-$ & $0.00 * *$ \\
& & & 3.07 & \\
Impact on life planning & $3.10 \pm 0.97$ & 1.56 & $1.42-$ & $0.00 * *$ \\
& & & 1.72 & \\
\hline Impact of PHEIC & $3.26 \pm 0.84$ & 1.49 & $1.33-$ & $0.00 * *$ \\
& & & 1.67 &
\end{tabular}

OR: odds ratio; $\mathrm{Cl}$ : confidence interval;*: $\mathrm{p}<0.1 ; * *: \mathrm{p}<0.05$

\subsection{Multivariate correlates of PTSD}

A multivariate analysis controlling for all significant variables in the bivariate analysis was also undertaken (Table 5). Self-reported fair or poor health $(A O R=1.78, P=0.00)$ and had confirmed cases among relatives and friends ( $A O R=7.70, P=0.03$ ) were positively associated with $P T S D$, whereas perceived social support from family $(A O R=0.81, P=0.00)$ and had high knowledge score $(A O R=0.73$, $\mathrm{P}=0.00$ ) were negatively associated with PTSD. 
High concern about COVID-19, beliefs that 'COVID-19 can cause a global outbreak' ( $A O R=1.66, P=0.00$ ) and 'impact of closed management on life' $(A O R=1.26, P=0.03)$ were positively associated with PTSD. Concerns that 'risk of infection', 'impact on life planning' and 'impact of PHEIC' were all positively associated with PTSD (AOR=2.46, 1.29 and 1.22, $\mathrm{P}=0.00$ ). Major in school, ever been quarantined or isolated and had close relatives and friends in key epidemic areas were not related to PTSD at the multivariate level. 
Table 5

Multvariate predictors of PTSD during the epidemic $(\mathrm{N}=2205)$

\begin{tabular}{|c|c|c|c|}
\hline \multirow[t]{2}{*}{ Variables } & \multicolumn{3}{|c|}{ PTSD } \\
\hline & AOR & $95 \% \mathrm{Cl}$ & $\mathbf{P}$ \\
\hline \multicolumn{4}{|l|}{ Major } \\
\hline Medical & 1 & & \\
\hline Non-medical & 1.15 & $0.94-1.41$ & 0.17 \\
\hline \multicolumn{4}{|l|}{ Health condition } \\
\hline Good health & 1 & & \\
\hline Fair or poor health & 1.78 & $1.22-2.59$ & $0.00 * *$ \\
\hline \multicolumn{4}{|c|}{ Perceived social support } \\
\hline Family & 0.81 & $0.70-0.93$ & $0.00 * *$ \\
\hline Friends & 1.14 & $0.96-1.36$ & 0.14 \\
\hline Significant other & 1.06 & $0.89-1.27$ & 0.51 \\
\hline \multicolumn{4}{|c|}{ Ever been quarantined or isolated } \\
\hline No & 1 & & \\
\hline Yes & 1.08 & $0.88-1.32$ & 0.45 \\
\hline \multicolumn{4}{|c|}{ Have close relatives and friends in key epidemic areas } \\
\hline No & 1 & & \\
\hline Yes & 1.32 & $0.79-2.19$ & 0.29 \\
\hline \multicolumn{4}{|c|}{ Confirmed cases among relatives and friends } \\
\hline No & 1 & & \\
\hline Yes & 7.70 & $1.28-46.25$ & $0.03^{\star *}$ \\
\hline \multicolumn{4}{|c|}{ Knowledge of COVID-19 } \\
\hline Score $<11$ & 1 & & \\
\hline Score $\geq 11$ & 0.73 & $0.60-0.90$ & $0.00 * *$ \\
\hline \multicolumn{4}{|l|}{ Levels of concern } \\
\hline Less concern & 1 & & \\
\hline High concern & 1.66 & $1.35-2.03$ & $0.00 * *$ \\
\hline
\end{tabular}




\begin{tabular}{|c|c|c|c|}
\hline Variables & \multicolumn{3}{|c|}{ PTSD } \\
\hline No & \multicolumn{3}{|l|}{1} \\
\hline Yes & 1.26 & $1.02-1.56$ & $0.03^{* *}$ \\
\hline \multicolumn{4}{|c|}{ Impact of closed management on life } \\
\hline No & \multicolumn{3}{|l|}{1} \\
\hline Yes & 1.37 & $1.12-1.68$ & $0.00 * \star$ \\
\hline \multicolumn{4}{|l|}{ Perceived threat } \\
\hline Risk of infection & 2.46 & $2.16-2.81$ & $0.00 * *$ \\
\hline Impact on life planning & 1.29 & $1.15-1.44$ & $0.00 * *$ \\
\hline Impact of PHEIC & 1.22 & $1.08-1.39$ & $0.00 * \star$ \\
\hline
\end{tabular}

\section{Discussion}

The findings of this study highlighted the major psychological challenges faced by Chinese college girls during the containment Stage of the COVID-19 pandemic. Compared to the similar domestic and overseas studies, the prevalence of PTSD symptoms in this study was relatively high, nearly one-third of participants met the cut-off for PTSD $[9,10,28,29]$. This might be partly due to the timing of the study, which was carried out at the early stages of the COVID-19 outbreak. At that time, the overall understanding to the disease, and the corresponding measures of prevention and control to the epidemic was still unclear. In addition, females are more prone to acute stress during major public health emergencies, such as SARS and earthquakes [30,31]. Furthermore, the international influence of the COVID-19 pandemic and its impact on people's lives are unprecedented, hence the short-term response of females is so overwhelming that they were likely to develop ASD, and eventually PTSD symptoms if it persists for a period of time. Suffering from PTSD will undoubtedly affect female college students' physical and mental health, academic performance and work plan, and even their future lives. Therefore, identifying risk factors at the beginning of the epidemic, offering targeted psychological counseling, providing appropriate psychological support and theory-based interventions during the rehabilitation process is particularly important.

People with fair or bad health were not only susceptible to the COVID-19 infection (especially with the lack of proper protection) but also had a poor prognosis once diagnosed. The study results were in line with the previous study that PTSD symptoms were remarkably high among those who perceived themselves not very healthy [32]. During the closed-off period, unhealthy participants might have the need to seek medical treatment or other health services, however, it may become a little difficult due to the 
traffic control and shortage of medical care in this extraordinary situation $[33,34]$ With the absence of medical care and medical supply during the epidemic, these unhealthy population were at an increased risk of PTSD symptoms $[35,36]$. Therefore, in the COVID-19 era, health officials should carefully weigh risks and benefits when planning medical needs of vulnerable population and chronic patients during the containment period. Basic medical services for these people should be ensured and thus releive their mental stress to avoid the extra burden of other diseases apart from the epidemic.

Consistent with the González-Sanguino C's study, our results revealed that those who had confirmed cases among relatives and friends were prone to have PTSD symptoms, which was found to be one of the strongest predictors of adverse psychological impacts during pandemic of infectious diseases [17]. When something stressful and terrifying happens around someone, they may fell frightened and helpless since they are themselves positively affected by the event $[37,38]$. Therefore, they are likely to go into the 'crisis phase' which is characterized by crying, stressful, insomnia and nightmares, and eventually develop symptoms of PTSD if conditions persist [30,39,40]. This reminds us that we should identify and focus on female college students who have COVID-19 patients among close relatives and friends, guide them to adjust their mentality, divert attention, and provide social support to encourage them to re-plan their lives under existing conditions [41].

Additionally, our self-developed COVID-19-related perceived threat scale uniquely predicted PTSD symptoms among young females, underscoring how the specific features of this pandemic give rise to acute and post-traumatic stress. Participants were not only worried about accidentally getting infected by 2019-nCoV, but also worried that their work and life arrangements would be affected by the growing epidemic. Long-term accumulation of adverse emotions would finally lead to PTSD symptoms including intrusion, avoidance and hyper-arousal, if symptoms persist [32, 40]. There is an urgent need to understand the mechanisms behind their potential PTSD symptoms and formulate specific interventions accordingly. First, the official media, schools and teachers should strengthen the publicity of preventive measures to reduce their perceived infection risks; second, the network structure of online teaching and job recruitment should be improved to alleviate the target population's concerns about future plans, and to ensure their normal paces of study and work; finally, the government should show confidence to the public in coping with the economic downturn due to the pandemic and provide appropriate subsidies to minimize the impact of the epidemic on individuals, such as measures the UK and Australia adopted [42, 43].

In current study, most of the respondents had high levels of social support, and the support from family, but not from partner or peers was negatively associated with PTSD symptoms, the same trend had been found among U.S. young adults during the COVID-19 pandemic [28]. College students were in home quarantine during the study period, substantial support and security might be important in maintaining the mental health of young adults because many were faced with acute stress and broken rhythm of life, such as holiday extension, financial pressure, undergraduate and unemployment. Emotional support coupled with material security provided by family would be an important factor in protecting them against the risk of PTSD. In contrast, peers may have difficult to provide material and living security 
considering that they are also young adults experiencing similar struggles. Therefore, family support should be addressed in the whole society to guanrantee psychological wellbeing of college female students during the pandemic.

Another protective factor for PTSD symptoms found from this study was high level of knowledge on COVID-19. With easy access to the internet, the majority of respondents can get instant updates on news related to the COVID-19 outbreak, and these real-time effective information can help keeping students informed on the epidemic, the role of information seemed to be fundamental to cope with the epidemic mentally and physically. A negative relationship between sufficient knowledge and adverse psychological impact of the pandemic was also found in researches conducted by Wang $\mathrm{C}$ and González-Sanguino $\mathrm{C}$ $[15,16,44]$. However, it should be cautious on the infodemic $[45,46]$. Social platforms play an important role in information acquisition and dissemination during the epidemic. Though the information from various sources and platforms are updated in real time, it lacks quality control sometimes. When we are surrounded by information noise, which may have impact on our emotions and behavior, such as the looting of Shuanghuanglian in the early stage of the epidemic in China, worries, fear and panic driven by false information may cause people to develop PTSD symptoms. Therefore, it is necessary to ensure that up-to-date, accurate and scientific information can be obtained from reliable sources to avoid panic caused by insufficient and inaccurate information and knowledge.

This study has several limitations to acknowledge. First, the generalizability of our conclusions is impacted given the results were possibly due in part to nonrandom selection of the sample, the possibility of sampling bias should be considered. Second, the uncontrolled online observational study of college students and the cross-sectional nature of the data warrant further longitudinal studies to determine the predictors of PTSD symptoms during the outbreak. Furthermore, the different psychological scales used in this studies may lead to different measurement outcomes compare to other similar studies. Finally, this study relied on anonymous network responses and self-reported answers regarding experience during home-quarantine stay which may not align with clinical psychological diagnosis.

In summary, the findings from this study provide a basis for implementing measures to improve the mental health among college female students during the outbreak of COVID-19 and have a reference value for identifying students who may have a high risk of adverse psychological problems. Our study has a number of strengths, including a large sample size and robust statistical analysis. Additionally, in order to verify the relationship between knowledge of COVID-19 and PTSD, we have designed a 14-item COVID-19-related knowledge and behavior questionnaire, including basic information about COVID-19, main symptoms, routes of transmission, and health behaviors to deal with COVID-19 infection. The results of the study demonsrated that the high-levle knowledge on COVID-19 is of most importance in protecting against the PTSD among female college students. Finally, taking the characteristics of college female students into account, we have developed the 10-item perceived threat scale with three dimensions, and its validity has also been confirmed in this research.

\section{Conclusions}


During the containment stage of the COVID-19 pandemic, this observational cross-sectional study revealed that more than one-third of participants suffered from PTSD symptoms. College female students who were unhealthy, highly concerned about the outbreak, had confirmed cases among relatives and friends, held an pessimistic attitude towards the epidemic and perceived threat of COVID-19 were all associated with PTSD symptoms. While proper knowledge of COVID-19 and perceived support from family were protectors for PTSD symptoms. Our findings can provide a basis for further exploration and designing of psychological intervention approaches to reduce the risk of obtaining PTSD and to improve mental health of college female students during epidemics of infectious disease.

\section{Abbreviations}

\section{COVID-19}

Coronavirus Disease 2019

WHO

World Health Organization

PHEIC

Public Health Emergency of International Concern

PTSD

Posttraumatic stress disorder

MSPSS

The Multidimensional Scale of Perceived Social Support

\section{IES-6}

Impact of Event Scale- 6

IES-R

Impact of Event Scale-revised

SD

Standard deviation

$P$

Probability

\section{Declarations}

Ethics approval and consent to participate This study was approved by the Ethics Committee of Jining Medical University of Shandong Province on February 12th, 2020, right before the initiation of the study (approval number: JNMC-2020-KY-001). After passing the qualification review and voluntarily providing the electronic informed consent, potential participants were directed to complete the self-reported questionnaire.

Consent for publication Not applicable. 
Availability of data and materials The original data generated from this study and the analyzed results will be available from the corresponding author upon reasonable request.

\section{Competing interests None.}

Funding Asian Regional Special Cooperation Fund of National Health Commission of the People's Republic of China (BLXM01) and Innovation Fund for Medical Sciences sponsored by Chinese Academy of Medical Sciences (2020-I2M-2-015, 2019-12M-2-005).

Authors' contributions Xiao-You Su, Ming-Yu Si prepared the first draft. You-Lin Qiao provided overall guidance. You-Lin Qiao, Xiao-You Su, Wen-Jun Wang and Ming-Yu Si managed the overall project. XiaoYou Su, Wen-Jun Wang, Xiao-Fen Gu, Li Ma, Jing Li, Shao-Kai Zhang and Ze-Fang Ren were responsible for the questionnaire survey of people in seven geographical regions of China. Xiao-You Su and Ming-Yu Si analyzed data. Yu Jiang and Yuan-Li Liu finalized the manuscript on the basis of comments from other authors.

AcknowledgementsNot applicable.

\section{References}

1. WHO. COVID-19 Weekly Epidemiological Update, 17 November. 2020. https://www.who.int/publications/m/item/weekly-epidemiological-update-17-november-2020 (accessed November 18, 2020).

2. National Health Commission of the People's Republic of China. Nov 16: Daily briefing on novel coronavirus cases in China. http://en.nhc.gov.cn/2020-11/16/c_82153.htm (accessed November 18, 2020).

3. World Health Organization (WHO).WHO characterizes COVID-19 as a pandemic, [EB/OL]. Geneva, Switzerland: World Health Organization; 2020. https://www.who.int/emergencies/diseases/novelcoronavirus-2019/events-as-they-happen (accessed June 28, 2020).

4. Luo M, Guo L, Yu M, et al. The psychological and mental impact of coronavirus disease 2019 (COVID-19) on medical staff and general public - A systematic review and meta-analysis. Psychiatry Res. 2020;291:113190. doi:10.1016/j.psychres.2020.113190.

5. Vindegaard N, Benros ME. COVID-19 pandemic and mental health consequences: Systematic review of the current evidence. Brain Behav Immun. 2020;89:531-42. doi:10.1016/j.bbi.2020.05.048.

6. Xiong J, Lipsitz O, Nasri F, et al. Impact of COVID-19 pandemic on mental health in the general population: A systematic review. J Affect Disord. 2020;277:55-64. doi:10.1016/j.jad.2020.08.001.

7. Khan AH, Sultana MS, Hossain S, et al. The impact of COVID-19 pandemic on mental health \& wellbeing among homequarantined Bangladeshi students: A cross-sectional pilot study. J Affect Disord. 2020 Dec 1;277:121-128. doi: 10.1016/j.jad.2020.07.135. 
8. Huckins JF, daSilva AW, Wang W, et al. Mental Health and Behavior of College Students During the Early Phases of the COVID-19 Pandemic: Longitudinal Smartphone and Ecological Momentary Assessment Study. J Med Internet Res. 2020 Jun 17;22(6):e20185. doi: 10.2196/20185.

9. Chi X, Becker B, Yu Q, et al. Prevalence and Psychosocial Correlates of Mental Health Outcomes Among Chinese College Students During the Coronavirus Disease (COVID-19) Pandemic. Front Psychiatry. 2020 Aug 7;11:803. doi: 10.3389/fpsyt.2020.00803. PMID: 32848958; PMCID: PMC7427603.

10. Tang W, Hu T, Hu B, et al. Prevalence and correlates of PTSD and depressive symptoms one month after the outbreak of the COVID-19 epidemic in a sample of home-quarantined Chinese university students. J Affect Disord. 2020 Sep 1;274:1-7. doi: 10.1016/j.jad.2020.05.009.

11. Sun Y, Tao F, Hao J, Wan Y. The mediating effects of stress and coping on depression among adolescents in China. J Child Adolesc Psychiatr Nurs. 2010 Aug;23(3):173-80. doi:10.1111/j.17446171.2010.00238.x.

12. Li SH, Graham BM. Why are women so vulnerable to anxiety, trauma-related and stress-related disorders? The potential role of sex hormones. Lancet Psychiatry. 2017;4(1):73-82. doi:10.1016/S2215-0366(16)30358-3.

13. Riecher-Rössler A. Sex and gender differences in mental disorders. Lancet Psychiatry. 2017 Jan;4(1):8-9. doi:10.1016/S2215-0366(16)30348-0.

14. Bigalke JA, Greenlund IM, Carter JR. Sex differences in self-report anxiety and sleep quality during COVID-19 stay-at-home orders. Biol Sex Differ. 2020;11(1):56. Published 2020 Oct 13. doi:10.1186/s13293-020-00333-4.

15. Wang C, Pan R, Wan X, et al. Immediate Psychological Responses and Associated Factors during the Initial Stage of the 2019 Coronavirus Disease (COVID-19) Epidemic among the General Population in China. Int J Environ Res Public Health. 2020 Mar 6;17(5):1729. doi: 10.3390/ijerph17051729.

16. Liu N, Zhang F, Wei C, et al. Prevalence and predictors of PTSS during COVID-19 outbreak in China hardest-hit areas: Gender differences matter. Psychiatry Res. 2020 May;287:112921. doi: 10.1016/j.psychres.2020.112921.

17. González-Sanguino $C$, Ausín $B$, Castellanos $M$, et al. Mental health consequences during the initial stage of the 2020 Coronavirus pandemic (COVID-19) in Spain. Brain Behav Immun. 2020 Jul;87:172-176. doi: 10.1016/j.bbi.2020.05.040.

18. Garza K, Jovanovic T. Impact of Gender on Child and Adolescent PTSD. Curr Psychiatry Rep. 2017 Sep 30;19(11):87. doi: 10.1007/s11920-017-0830-6.

19. Farhood L, Fares S, Hamady C. PTSD and gender: could gender differences in war trauma types, symptom clusters and risk factors predict gender differences in PTSD prevalence? Arch Womens Ment Health. 2018 Dec;21(6):725-733. doi: 10.1007/s00737-018-0849-7.

20. Charak R, Armour C, Elklit A, et al. Factor structure of PTSD, and relation with gender in trauma survivors from India. Eur J Psychotraumatol. 2014 Nov 17;5:25547. doi: 10.3402/ejpt.v5.25547. 
21. Thoresen S, Tambs K, Hussain A, et al. Brief measure of posttraumatic stress reactions: Impact of Event Scale-6. Social Psychiatry and Psychiatric Epidemiology 2010, 45(3):405-412. doi: 10.1007/s00127-009-0073-x.

22. Needham DM, Sepulveda KA, Dinglas VD, et al. Core Outcome Measures for Clinical Research in Acute Respiratory Failure Survivors. An International Modified Delphi Consensus Study. Am J Respir Crit Care Med. 2017;196(9):1122-30. doi:10.1164/rccm.201702-03720C.

23. Zhan $S$, Wu T, Ren T, et al. [The cross-sectional study of awareness and practice of SARS epidemic in community residents in Beijing]. Beijing Da Xue Xue Bao Yi Xue Ban. 2003 May 31;35 Suppl:95 - 8. Chinese. PMID: 12914230.

24. Liu ZR, Huang YQ, Dang WM, et al. [Study on the psychosocial status and related factors in three universities during severe acute respiratory syndrome epidemic in Beijing]. Zhonghua Liu Xing Bing Xue Za Zhi. 2004 Jul;25(7):594-7. Chinese. PMID: 15308040.

25. Smith RD. Responding to global infectious disease outbreaks. lessons from SARS on the role of risk perception, communication and management. Soc Sci Med. 2006 Dec;63(12):3113-23.

doi:10.1016/j.socscimed.2006.08.004.

26. Zimet GD. Powell SS, Farley GK, et al Psychometric characteristics of the Multidimensional Scale of Perceived Social Support. J Pers Assess. 1990 Winter,55(3-4):610-7. doi: 10.1080/00223891.1990.9674095.

27. Chou KL. Assessing Chinese adolescents' social support. the multidimensional scale of perceived social support. Personality Individ Differ. 2000;28:299-307.

28. Liu CH. Zhang E, Wong GTF, et al Factors associated with depression, anxiety, and PTSD symptomatology during the COVID-19 pandemic: Clinical implications for U.S. young adult mental health. Psychiatry Res. 2020 Aug,290:113172. doi: 10.1016/j.psychres.2020.113172.

29. Wathelet M, Duhem S, Vaiva G, et al. Factors Associated With Mental Health Disorders Among University Students in France Confined During the COVID-19 Pandemic. JAMA Netw Open. 2020 Oct 1,3(10):e2025591. doi: 10.1001/jamanetworkopen.2020.25591.

30. Mak IW. Chu CM, Pan PC, et al Risk factors for chronic post-traumatic stress disorder (PTSD) in SARS survivors. Gen Hosp Psychiatry. 2010 Nov-Dec,32(6):590-8. dor:

10.1016/j.genhosppsych.2010.07.007.

31. Rafiey H. Alipour F, LeBeau R, et al Prevalence and Determinants of PTSD 3 Years After an Earthquake in Iran. Community Ment Health J. 2019 Apr;55(3):542-547. doi: 10.1007/s10597-01900384-x.

32. Post LM. Zoellner LA, Youngstrom E, et al Understanding the relationship between co-occurring PTSD and MDD: symptom severity and affect. J Anxiety Disord 2011 Dec,25(8):1123-30. doi: 10.1016/j.janxdis.2011.08.003.

33. Palmer K, Monaco A, Kivipelto M, et al. The potential long-term impact of the COVID-19 outbreak on patients with non-communicable diseases in Europe: consequences for healthy ageing. Aging Clin Exp Res. 2020 Jul;32(7):1189-1194. doi: 10.1007/s40520-020-01601-4. 
34. Du L. Cheng Z, Zhang Y, et al The impact of medication adherence on clinical outcomes of coronary artery disease: A meta-analysis. Eur J Prev Cardiol. 2017 Jun,24(9):962-70. doi: $10.1177 / 2047487317695628$.

35. Extance A. Covid-19 and long term conditions: what if you have cancer, diabetes, or chronic kidney disease? BMJ. 2020 Mar 25;368:m1174. doi: 10.1136/bmj.m1174.

36. Williams FMK. Muirhead N, Pariante C. Covid-19 and chronic fatigue. BMJ. 2020 Jul 30;370:m2922. doi: 10.1136/bmj.m2922.

37. Bond S. Gourlay C, Desjardins A, et al Anxiety, depression and PTSD-related symptoms in spouses and close relatives of burn survivors: When the supporter needs to be supported. Burns. 2017 May;43(3):592-601. doi: 10.1016/j.burns.2016.09.025.

38. Bäckström J. Ekselius L, Gerdin B, et al Prediction of psychological symptoms in family members of patients with burns 1 year after injury. J Adv Nurs. 2013 Feb,69(2):384 - 93. dor: 10.1111/j.13652648.2012.06017.x.

39. Sundara DC. A review of issues and concerns of family members of adult burn survivors. $J$ Burn Care Res. 2011 May-Jun;32(3):349 - 57. doi: 10.1097/BCR.0b013e318217f6cb.

40. Bryant RA. The Current Evidence for Acute Stress Disorder. Curr Psychiatry Rep. 2018 Oct 13;20(12):111. doi: 10.1007/s11920-018-0976-x.

41. Paparrigopoulos T, Melissaki A, Efthymiou A, et al. Short-term psychological impact on family members of intensive care unit patients. J Psychosom Res. 2006 Nov;61(5):719 - 22. doi: 10.1016/j.jpsychores.2006.05.013.

42. Costa Dias M, Joyce R, Postel-Vinay F, et al. The Challenges for Labour Market Policy during the COVID-19 Pandemic. Fisc Stud. 2020 Jul 14:10.1111/1475-5890.12233. doi: 10.1111/14755890.12233

43. Andrikopoulos S. Johnson G. The Australian response to the COVID-19 pandemic and diabetes Lessons learned. Diabetes Res Clin Pract. 2020 Jul,165:108246. doi: 10.1016/j.diabres.2020.108246.

44. Wang C. Pan R, Wan X, et al A longitudinal study on the mental health of general population during the COVID-19 epidemic in China. Brain Behav Immun. 2020 Jul,87:40-8. doi: 10.1016/j.bbi.2020.04.028.

45. Gallotti R, Valle F, Castaldo N, et al. Assessing the risks of 'infodemics' in response to COVID-19 epidemics. Nat Hum Behav. 2020 Oct 29. dor: 10.1038/s41562-020-00994-6

46. Patel MP, Kute VB, Agarwal SK; COVID-19 Working Group of Indian Society of Nephrology. "Infodemic" COVID 19: More Pandemic than the Virus. Indian J Nephrol. 2020 May-Jun;30(3): 188191. doi: 10.4103/ijn.IJN_216_20.

\section{Supplementary Files}

This is a list of supplementary files associated with this preprint. Click to download. 
- Appendix.docx

Page 27/27 